\title{
NÍVEL MOTOR DE ESTUDANTES EM UMA ESCOLA DA ZONA RURAL DO MUNÍCIPIO DE PICOS-PI
}

\author{
MOTOR LEVEL OF STUDENTS IN A SCHOOL IN THE RURAL AREA OF THE \\ MUNICIPALITY OF PICOS-PI
}

\author{
Ana Kariele da Silva Santos ${ }^{\mathrm{I}}$ \\ Edênia Raquel Barros Bezerra de Moura ${ }^{2}$ \\ Nélida Amorim da Silva ${ }^{3}$ \\ Glauber Castelo Branco Silva ${ }^{4}$ \\ Luciano Silva Figueiredo5 \\ Renata Louise Ferreira Lemos ${ }^{6}$
}

RESUMO: O estudo objetivou caracterizar o desenvolvimento motor de escolares entre o4 a 07 anos, mediante a aplicação de testes educativos em uma escola pública municipal na cidade de Picos-PI. Trata-se de um estudo descritivo, desenvolvido na U. E. Helvídio Nunes de Barros, no povoado de Fátima do Piauí, com 6o crianças, de acordo com o critério de inclusão. Os escolares realizaram testes psicomotores, de acordo com a EDM de Rosa Neto (2015), a fim de estimularem o seu desenvolvimento motor através das atividades recreativas, por meio da estimulação da motricidade fina e global, o equilíbrio, o esquema corporal, a organização espacial e temporal e a lateralidade. Após os testes,

I Graduada em Licenciatura em Educação Física pela Universidade Estadual do Piauí - UESPI/Picos. Monitora do Programa Mais Educação da Secretaria Municipal de Educação de Picos-PI. Email: anakarielesantos@gmail.com.

${ }^{2}$ Especialista em Saúde Pública com Ênfase na Estratégia de Saúde da Família pelo Instituto de Educação Superior Raimundo Sá - Picos/PI. Mestranda no Programa de Pós-Graduação em Formação de Professores e Práticas Interdisciplinares pela Universidade Estadual do Pernambuco -UPE/Petrolina. Professora do quadro efetivo no Curso de Licenciatura em Educação Física na Universidade Estadual do Piauí UESPI/Picos. Email: edeniaraquel@pcs.uespi.br

${ }^{3}$ Mestre em Educação Física pela Universidade de Brasília - UnB. Doutoranda em Engenharia Biomédica pela Universidade Brasil. Professora do quadro efetivo no Curso de Licenciatura em Educação Física na Universidade Estadual do Piauí - UESPI/Picos. Email: nelida@pcs.uespi.br

${ }^{4}$ Doutor em Educação Física pela Universidade Católica de Brasília, Brasil. Professor do quadro efetivo no Curso de Licenciatura em Educação Física na Universidade Estadual do Piauí - UESPI/Picos. Email: glaubercastelobsilva@hotmail.com

5 Doutor em Ciências pela Universidade Federal do Rio Grande do Sul, Brasil. Professor permanente junto ao Mestrado Profissionalizante em Ensino de Biologia (PROFBIO).

Colaborador no Programa de Pós-Graduação em Desenvolvimento e Meio Ambiente (TROPEN) na Universidade Federal do Piauí. Professor do quadro efetivo no Curso de Bacharelado em Ciências Biológicas na Universidade Estadual do Piauí - UESPI/Picos. Email: lucfigueireddo@uol.com.br

${ }^{6}$ Especialista em Nutrição Clínica e Funcional pelo Centro Universitário Santo Agostinho - UNIFSA.

Especialista em Desporto Escolar pelo Instituto Federal do Piauí - IFPI. Professora do quadro efetivo no Curso de Licenciatura em Educação Física na Universidade Estadual do Piauí - UESPI/Picos.

Email; renatalouise@pcs.uespi.br. 
observou-se que a maioria dos escolares se encontra dentro da normalidade, tendo o elemento psicomotor da organização espacial com a maior porcentagem de desempenho entre os avaliados, enquanto a motricidade fina apresentou-se com menor percentual de desempenho. Nesse sentido, o brincar está escasso na vida das crianças, percebendo-se pela ausência de um ambiente favorável à prática, logo foi proporcionado às mesmas um momento prazeroso com os testes psicomotores.

Palavras chaves: Habilidades Motoras. Rendimento Escolar. Psicomotricidade. Elementos da Aprendizagem Motora.

ABSTRACT: The study aimed to characterize the motor development of students between 4 and 7 years old, by applying educational tests in a municipal public school in the city of Picos-PI. This is an observational, cross-sectional study, conducted at U. E. Helvídio Nunes de Barros, in the village of Fátima do Piauí, with 6o children, according to the inclusion criteria. The students underwent psychomotor tests, according to Rosa Neto's EDM (2015), in order to stimulate their motor development through recreational activities, through stimulation of fine and global motor skills, balance, body scheme, spatial and temporal organization and laterality. After the tests, it was observed that most students are within normal range, with the psychomotor element of spatial organization having the best performance among the evaluated, while the fine motricity presented the lowest performance. In this sense, playing is scarce in the lives of children, being perceived by the absence of a favorable environment for the practice, so they were provided a pleasant moment with the psychomotor tests.

Keywords: Child Development. Motor skills. School Performance. Psychomotricity. Elements of Motor Learning.

\section{INTRODUÇÃO}

É notório saber que o desenvolvimento motor incorpora mudanças desde o momento da concepção, o qual resulta no processo de aprender e no aprimoramento da maturação do corpo (GALLAHUE; OZMUN; GOODWAY, 2013), sendo favorável por meio da psicomotricidade, a qual é caracterizada pela capacidade que permite a criança socializar-se, agir consigo e com o outro perante as experiências vividas em meio ao seu próprio processo de maturação (LUSSAC, 2008).

A psicomotricidade é a ciência que tem como objeto de estudo o homem e seu movimento, um meio preventivo de déficits na aprendizagem e no desenvolvimento motor (BESSA; MACIEL, 2016), contribuindo dialeticamente na construção do aspecto motor (o corpo) e da mente (a emoção e a inteligência), facilitando a comunicação do indivíduo com o mundo a partir da otimização corporal e dos potenciais neuro e psico-cognitivos organizados e integrados (COSTA JR; DIRCEU, 2017).

Segundo Gallahue e Ozmun (200I), o desenvolvimento da criança é um processo 
de mudanças comportamentais e/ou estruturais. Para os autores supracitados, entender o desenvolvimento motor de uma criança e compreender o movimento. Logo, conforme Caetano; Silveira; Gobbi (2005), o desenvolvimento motor ocorre da interação do movimento.

Com o ambiente, estando atrelado aos elementos básicos da psicomotricidade, a saber: a motricidade fina, a motricidade global, o equilíbrio, o esquema corporal, a organização espacial, a organização temporal e a lateralidade. Todavia, através da interação desses elementos com o movimento e o ambiente, o desenvolvimento da criança será favorável ao seu processo de evolução.

A contribuição da psicomotricidade nos anos iniciais é de grande valia, pois é trabalhada de maneira expressiva intensificando todas as etapas do processo do desenvolvimento físico motor.

Dessa forma, faz-se necessário estimular os elementos supracitados ainda nos primeiros anos da infância por serem necessários ao desenvolvimento motor e global da criança, seja através de atividades recreativas, brincadeiras e jogos, levando a mesma a um completo desenvolvimento e aperfeiçoamento da aprendizagem.

Nessa perspectiva, a Educação Física é uma área estratégica no campo da psicomotricidade, tendo no movimento o meio mais significativo para aprendizagem. O profissional de Educação Física defende a importância do desenvolvimento psicomotor durante os cinco primeiros anos da infância, pois é nesse período que ocorrem as mais significativas aquisições a nível físico, emocional e intelectual.

No seu processo pedagógico, trabalhando a psicomotricidade, o professor de Educação Física estará proporcionando uma melhor qualidade na infância, além de proporcionar a partir do movimento, condições de desenvolvimento dos seus aspectos básicos e necessários para a vida adulta, afinal, a psicomotricidade é indispensável a toda criança em seu processo de formação (XISTO; BENETTI, 20I2).

A escolha do tema foi objetivado através do contato com as crianças desde o início da graduação, no qual foi perceptível a falta de estimulação do desenvolvimento motor por meio de atividades recreativas que, consequentemente, poderiam comprometer o processo de aprendizagem e o rendimento escolar.

Diante do exposto, o estudo visou caracterizar o desenvolvimento motor de escolares na faixa etária de 04 a 07 anos, mediante aplicação de testes motores educativos em uma escola da rede pública de ensino no município de Picos-PI.

\section{Procedimentos metodológicos \\ Tipo de estudo}

Trata-se de uma pesquisa de abordagem qualitativa com caráter descritivo, 
que em sua maioria, permite ao pesquisador um maior contato e aproximação com a realidade originária dos dados por ser realizada no local onde surgem os mesmos. Tem como objetivo a interpreração e descrição de um complexo conjunto de informações coletadas (NEVES, 1996).

Área de estudo e população amostral

O estudo foi realizado na rede pública de ensino do município de Picos-PI, especificamente no povoado de Fátima do Piauí, o mesmo possuindo aproximadamente

2.500 habitantes, situado a $12 \mathrm{~km}$ da cidade de Picos.

O município de Picos-PI é constituído por uma rede de ensino de escolas públicas e privadas desde o maternal ao ensino superior. A cidade dispõe de aproximadamente 62 escolas municipais, conforme censo populacional participaram da pesquisa 60 estudantes, entre 04 a 07 anos de idade de ambos os sexos e, regularmente matriculados na Educação Básica da Unidade Escolar Helvídio Nunes de Barros, zona rural de Picos, a qual atende escolares nos ensinos infantil e fundamental I e II, a mesma não dispõe de aulas de Educação Física para o ensino infantil e fundamental $\mathrm{I}$, apenas com atividades recreativas realizadas pelos professores polivalentes da devida escola.

A seleção da amostra foi mediante vivência prática no referido campo de estudo, no qual percebeu-se a ausência de atividades recreativas que estimulassem o desenvolvimento motor dos escolares. Adotou-se a quantidade supracitada por se tratar das turmas mais numerosas da escola, além da faixa etária atender ao critério de classificação de desempenho motor estabeledico por Rosa Neto (2015).

\section{Coleta de dados}

Os métodos de avaliação do desenvolvimento infantil são diversos, no entanto, nenhum é perfeito e muito menos engloba holisticamente todos os aspectos. Desta forma, para a coleta dos dados foram realizados testes motores a fim de diagnosticar os elementos básicos da psicomotricidade, conforme sugerido no Manual de Avaliação Motora sob autoria do Rosa Neto (2015).

O manual trabalha testes que variam do nível 2 ao II, no entanto, selecionouse apenas I nível de cada teste motor, de acordco com a idade cronologica da amostra.

Para avaliar a motricidade fina foi aplicado aos escolares da pesquisa o teste "Construção de uma torre", no qual o aluno teve de construir uma torre em 30 segundos, utilizando 6 cubos, em meio a 3 tentativas sem ultrapassar o tempo estimado (ROSA NETO, 2015).

A motricidade global foi examinada através da aplicação aos voluntários o 
teste "Caminhar em linha reta", no qual o aluno teve de percorrer 3 metros, colocando-se um pé na frente do outro sem perder o equilíbrio em 2 minutos, em meio a 3 tentativas sem ultrapassar o tempo estimado (ROSA NETO, 2015).

Para avaliar o equilíbrio foi aplicado aos alunos o teste "Pé manco estático", no qual o aluno teve de ficar em posição bípede com uma perna flexionada, devendo se manter nesta posição no tempo de o segundos, realizando-se o mesmo exercício com a outra perna, sem ultrapassar o tempo estimado (ROSA NETO, 2015).

O esquema corporal foi examinado através da aplicação aos escolares o teste "Imitação de gestos simples", na qual o examinador realizou gestos e o aluno teve de refazê-los, no tempo de ro segundos cada gesto (ROSA NETO, 2015).

Para analisar a organização espacial foi aplicado aos participantes o teste "Tabuleiro", no qual o aluno teve de colocar as figuras geométricas nos espaços no tempo de I minuto, utilizando um tabuleiro, em meio a 2 tentativas sem ultrapassar o tempo estimado (ROSA NETO, 2015).

Para analisar a organização temporal foi aplicado as crianças o teste "Reprodução de sons", no qual o examinador executou uma estrutura de sons e o aluno memorizava e repetia, na mesma velocidade, em meio a 2 tentativas a cada estrutura de som no tempo de I minuto sem ultrapassar o tempo estimado (ROSA NETO, 2015).

Para analisar a lateralidade foi aplicado aos alunos o teste "Lançar uma bola", na qual o aluno teve de lançar uma bola em 3 tentativas cada mão, direita e esquerda, no tempo de io segundos cada sem ultrapassar o tempo estimado (ROSA NETO, 2015).

\section{Critérios de inclusão}

Foram incluídos no estudo os escolares com a faixa etária entre 4 a 7 anos de ambos os sexos, cujos pais e/ou responsáveis aceitaram que os filhos participassem voluntariamente $\mathrm{da}$ pesquisa $\mathrm{e}$ que estivessem regularmente matriculados na Unidade Escolar Helvídio Nunes de Barros, campo de estudo, bem como, os escolares que participaram rigorosamente da metodologia proposta na coleta de dados.

\section{Tratamento de dados}

Os testes foram avaliados segundo o Manual de Avaliação Motora (ROSA NETO, 2015), este manual compreende avaliar o desenvolvimento motor de crianças entre 2 a II anos de idade. Mediante as provas de habilidade formada pela motricidade 
fina e global, equilíbrio, esquema corporal, organização espacial e temporal, bem como a lateralidade.

Este instrumento determina a idade motora geral (obtida por meio da soma dos resultados positivos expressados em meses conseguidos nas provas em todos os elementos da motricidade) e o quociente motor geral (obtido pela divisão entre a idade motora geral e idade cronológica; o resultado é multiplicado por ıoo). Esse conjunto de provas que fazem parte da EDM possui como características ser bem diversificada e de dificuldade graduada de acordo com a habilidade avaliada. (ROSA NETO, 2002).

Os dados foram desenvolvidos utilizando um ficha de avaliação (APÊNDICE A), seguindo uma escala numérica de o (zero) a 2 (dois), variando categoricamente entre os pontos positivo, parcialmente positivo e negativo, a saber: valor positivo, atribuído quando a criança conseguisse realizar o teste por completo e corretamente, atribuindo nota igual a 2 (dois); parcialmente postivo, quando a criança não conseguisse completar o teste, recebendo nota igua a I (um); valor negativo, caracterizado o teste no qual a criança não conseguisse realizar, conferindo nota igual a o (zero).

Foi utilizada uma estatística de porcentagem simples para representação dos dados nominais mediante avaliação do desenvolvimento motor dos escolares, bem como para elaboração dos gráficos e tabelas, ambos aplicados pelo Programa Microsoft Excel, versão 2oio.

\section{Aspectos éticos}

A pesquisa teve início após a autorização institucional da Secretaria Municipal de Educação (APÊNDICE B). Os pais e/ou responsáveis foram convidados a participarem de uma reunião na qual foram esclarecidos os objetivos e procedimentos metodológicos da pesquisa. Aqueles que aceitaram a participação do aluno como voluntário do estudo assinaram o (TCLE) Termo de Consentimento Livre e Esclarecido (APÊNDICE C). Após autorização dos pais e/ou responsáveis, foi questionado aos escolares se os mesmos queriam participar das atividades desenvolvidas pelo pesquisador, tendo aceitado, estes assinaram o (TALE) Termo de Assentimento Livre e Esclarecido (APÊNDICE D).

A pesquisa teve a adoção de procedimentos éticos com seres humanos de acordo com a Resolução do Conselho Nacional de Saúde (CNS/MS) no 466/ı2, sendo o estudo submetido e aprovado ao Comitê de Ética e Pesquisa (CEP) sob parecer no 3.814.991 e código do CAAE: 14607319.8.0000.5209, da Universidade Estadual do Piauí.

\section{Resultados e discussões}

Atendendo aos critérios de inclusão desta pesquisa, participaram do estudo 60 
escolares na faixa etária de 4 a 7 anos de ambos os sexos, sendo $51,6 \%$ da amostra apresentado por meninos e $48,4 \%$ por meninas, como segue apresentado na tabela abaixo:

Tabela I: Caracterização dos testes psicomotores de escolares distribuídos por sexo, no município de Picos-PI.

\begin{tabular}{|c|c|c|c|c|c|c|}
\hline \multirow{3}{*}{$\begin{array}{c}\text { Testes } \\
\text { Psicomotores }\end{array}$} & \multicolumn{6}{|c|}{ Grupos } \\
\hline & \multicolumn{3}{|c|}{ Masculino } & \multicolumn{3}{|c|}{ Feminino } \\
\hline & $\mathrm{P}^{*}$ & $\mathrm{PP} * *$ & $\mathrm{~N} * * *$ & $\mathrm{P}^{*}$ & $\mathrm{PP} * *$ & $\mathrm{~N} * * *$ \\
\hline $\begin{array}{c}\text { Motricidade } \\
\text { Fina }\end{array}$ & $93,4 \%$ & $3,3 \%$ & $3,3 \%$ & $93,2 \%$ & $3,4 \%$ & $3,4 \%$ \\
\hline $\begin{array}{c}\text { Motricidade } \\
\text { Global }\end{array}$ & $35,5 \%$ & $58,1 \%$ & $6,4 \%$ & $44,8 \%$ & $5 \mathrm{I}, 8 \%$ & $3,4 \%$ \\
\hline Equilíbrio & $9,7 \%$ & $71 \%$ & $19,3 \%$ & $37,9 \%$ & $55,1 \%$ & $7 \%$ \\
\hline $\begin{array}{l}\text { Esquema } \\
\text { Corporal }\end{array}$ & $45,2 \%$ & $45,2 \%$ & $9,6 \%$ & $65,5 \%$ & $27,5 \%$ & $7 \%$ \\
\hline $\begin{array}{c}\text { Organização } \\
\text { Espacial }\end{array}$ & $96,7 \%$ & - & $3,3 \%$ & $96,6 \%$ & - & $3,4 \%$ \\
\hline $\begin{array}{c}\text { Organização } \\
\text { Temporal }\end{array}$ & $22,5 \%$ & $74,2 \%$ & $3,3 \%$ & $44,8 \%$ & $44,8 \%$ & Io, $4 \%$ \\
\hline Lateralidade & $67,8 \%$ & - & $32,2 \%$ & $72,5 \%$ & - & $27,5 \%$ \\
\hline
\end{tabular}

Fonte: (dados da pesquisa, 2019).

*valor positivo. $* *$ valor parcialmente positivo. ***valor negativo.

De acordo com os testes aplicados, observou-se que o sexo feminino obteve os melhores resultados na maioria dos elementos psicomotores avaliados, evidenciando resultado positivo em $44,8 \%$ na motricidade global; $37,9 \%$ no equilíbrio; $65,5 \%$ no esquema corporal; $44,8 \%$ na organização temporal e $72,5 \%$ na lateralidade, assim representado na tabela I, sendo que a faixa etária de 4 anos foi a que alcançou um melhor percentual na execução dos testes.

Achados de Oliveira; Oliveira; Cattuzzo (2013), retratam que o sexo masculino se destaca melhor que o feminino em atividades de saltar, correr e caminhar, ao contrário do observado no presente estudo, o qual revelou desempenho satisfatório entre as meninas na habilidade de caminhar. Os autores afirmam, ainda, que um melhor desempenho motor foi visto em crianças com maior idade nas atividades de correr, saltar horizontalmente e deslize lateral. Já as meninas, na faixa etária de cinco anos se destacaram em saltitar com um pé, concluindo que atividades motoras mais complexas foram realizadas após as consideradas menos complexas. Observa-se também que crianças mais velhas obtiveram melhor desempenho do que crianças mais novas em todas as habilidades e no escore total locomotor. 
Sousa et al, (2014), afirmam que os meninos alcançaram melhor desempenho em atividades de manipular objetos e de locomoção como corrida, salto horizontal, rebatida, chute e arremesso apresentando uma média de $37,5 \%$ enquanto que as meninas, média de $33 \%$, saindo à frente somente no galope. Os dados corroboram com a pesquisa atual, a qual revelou que os meninos tiveram maior percentual de desempenho nos testes de controle de objetos do que as meninas, com desempenho positivo na motricidade fina de 93,2\%. No entanto, ao analisar a locomoção dos escolares, as meninas alcançaram melhor resultado, contradizendo, assim, o estudo do autor supracitado.

As crianças avaliadas no estudo apresentaram destreza manual bem desenvolvida conforme representado na tabela $\mathrm{I}$, contradizendo os achados de Oliveira; Cavalcante Neto e Palhares (2018), no qual afirmaram que crianças com Transtorno de Déficit de Atenção com Hiperatividade (TDAH) demonstraram uma baixa capacidade de destreza manual. Rosa Neto et al. (2008), afirmam que o TDAH é um dos maiores problemas enfrentados por crianças tendo em vista que as dificuldades existentes perpassam essa fase persiste até a adolescência e vida adulta, ao mesmo tempo compromete as habilidades motoras globais e finas, consequentemente, ocasionando uma desordem ou desarranjo no desenvolvimento motor (DM) e, assim, interferindo em diversas fases do desenvolvimento global da criança.

Relacionando o desenvolvimento motor às características psicossociais, Rosa et al. (2008), constataram que os maiores déficits se encontram na área do esquema corporal, organização espacial e organização temporal. Os meninos apresentaram maior déficit em equilíbrio, enquanto as meninas tiveram maior dificuldade em esquema corporal. Crianças de 4 a 12 anos com dificuldade de aprendizagem apresentaram perfil motor com desempenho inferior, tendo estas maior dificuldade no equilíbrio, esquema corporal, organização espacial e temporal.

$\mathrm{Na}$ área do desenvolvimento motor da criança pode-se, no estudo de Rosa et al. (2008), observar um considerável déficit motor, destacando-se as áreas de motricidade fina e motricidade global, já as áreas de esquema corporal e organização espacial apresentaram resultados positivos. Enquanto na presente pesquisa os maiores déficits são nas áreas de motricidade global, equilíbrio e organização temporal. Sendo os meninos com o maior déficit no equilíbrio enquanto as meninas na motricidade global.

Levitt (200I), analisou o desenvolvimento motor de uma criança com paralisia cerebral do tipo atáxica no meio aquático, sendo esta uma paralisia que tem por característica lesão no cerebelo, parte responsável por controlar movimentos, postura e equilíbrio. A amostra avaliada apresentou déficit motor preocupante, principalmente nas áreas da motricidade fina e motricidade global, as quais apresentaram um quociente motor de 30\%, resultado classificado pela (EDM) como "muito inferior", ou seja, a criança não apresentou avanços para com as atividades no programa do meio aquático. No entanto, na presente pesquisa, as crianças tidas como normais, 
apresentaram escores positivos na motricidade fina, porém, escores abaixo da média na motricidade global, corroborando com os estudos dos autores supracitados para este elemento motor.

A figura I caracteriza o desempenho geral dos escolares conforme cada elemento básico motor analisado. Assim, observa-se que dentre todos estes elementos, a organização espacial foi o que obteve maior escore positivo, afirmando que a amostra avaliada apresenta melhor domínio do espaço que o rodeia.

Figura r: Nível de desempenho motor de escolares considerando os elementos básicos da psicomotricidade. Picos-PI.

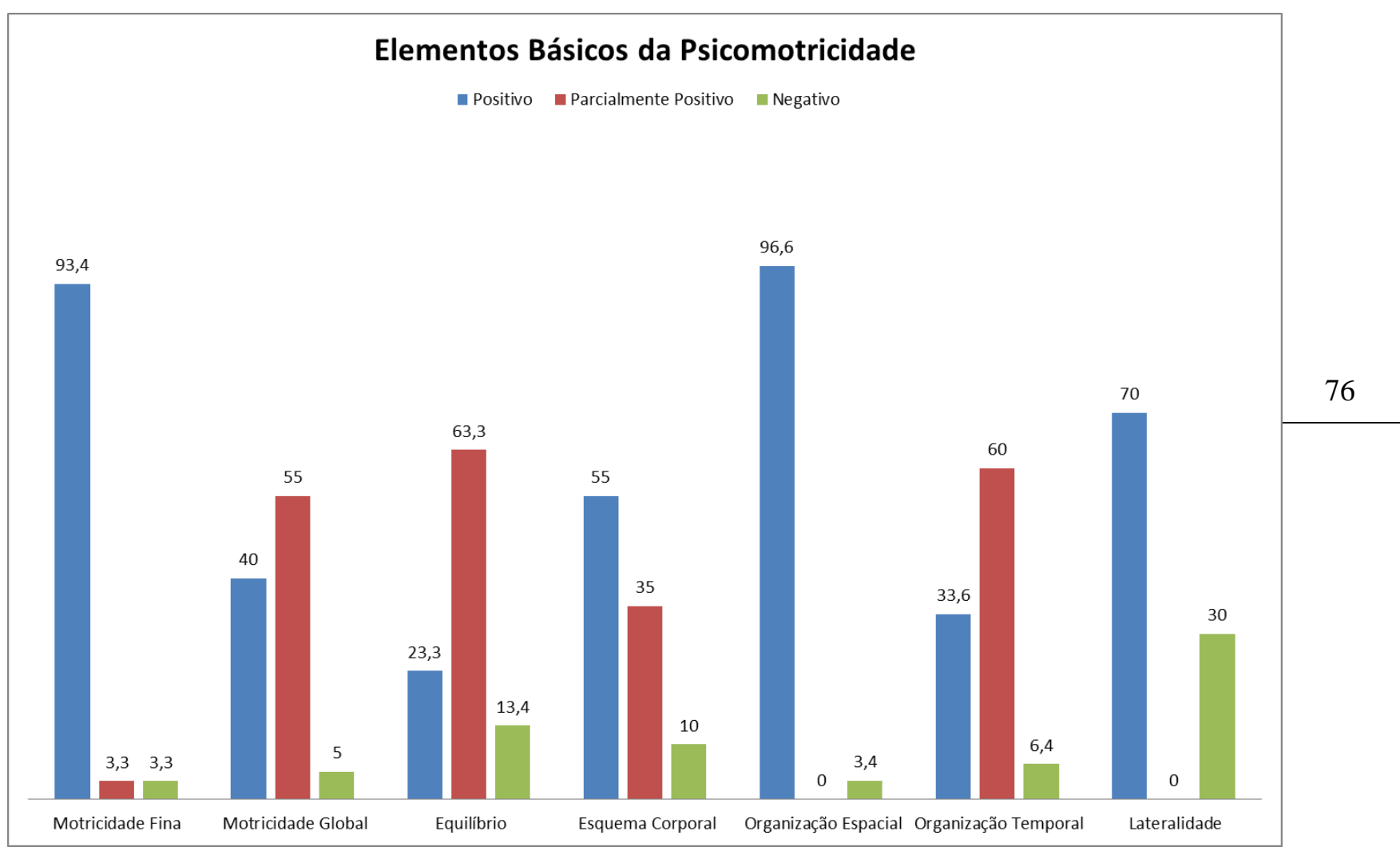

Fonte: (dados da pesquisa, 2019).

Como já mencionado no parágrafo anterior, a organização espacial foi o elemento psicomotor com o melhor desempenho entre os escolares, 96,6\% (figura I), revelando que a amostra têm plena noção do espaço mediante a realização da atividade do tabuleiro, representando $38,3 \%$ dos alunos de ambos os sexos, sendo, especificamente, a faixa etária de 4 anos a de melhor desempenho quanto a organização espacial.

No que concerne a motricidade fina, este apresentou-se como o elemento de 
menor escore parcialmente positivo e negativo 3,3\% (figura $\mathrm{I}$ ). Dentre os escolares avaliados, 02 não apresentaram a motricidade fina desenvolvida para a idade correspondente a 5 anos, mediante a atividade de construção de uma torre. Já nos achados de Silveira et al (2007), no qual aplicaram os testes psicomotores propostos por Rosa Neto (2002), com crianças na faixa etária de 2 a 6 anos, a motricidade fina foi o elemento motor que obteve o maior escore positivo, em torno de $80,5 \%$.

Rosa et al. (2008), ao analisarem o desenvolvimento motor em crianças, pode se observar um déficit motor preocupante, principalmente nas áreas de motricidade fina e global, as quais apresentaram um quociente motor de $30 \%$. Analisando a motricidade fina, conforme expressado na figura acima, os escolares avaliados obtiveram resultado positivo, demonstrando que quase a totalidade da amostra apresentou boa coordenação motora fina de acordo com sua respectiva idade cronológica.

Segundo Soccol (2009), no teste com 14 crianças, a média da motricidade fina foi de 94,2\%, bem próximo ao presente estudo, na qual levou a hipótese de que as crianças tiveram estímulos motores relacionados aos pequenos grupos musculares durante a infância, porém, muitas vezes podem ser prejudicados por influência de algumas variáveis, seja de ordem familiar, escolar ou social.

O autor acima ainda relata que faz-se necessário prestar atenção aos métodos e técnicas a serem trabalhados com crianças, tendo em vista que a aprendizagem das mesmas ocorre por meio da linguagem corporal. Por isso, deve-se estimular brincadeiras simples como o manusear objetos (brinquedos), o caminhar, a qual é uma das principais atividades de locomoção da criança, afinal envolve grandes grupos musculares na execução dos movimentos. Segundo Souza (2012), as brincadeiras que envolvem a locomoção, oferecem às crianças interações com os objetos, com as pessoas e, principalmente, com o meio a qual estão inseridas.

No estudo de Rocha, Zagato Neto (2012), dos alunos pesquisados, io na faixa etária de 6 anos, não apresentaram nível de desenvolvimento adequado para a motricidade global. No entanto, analisando este elemento motor na figura I, $55 \%$ dos escolares obtiveram resultado parcialmente positivo, demonstrando, assim, motricidade global razoavelmente adequada à idade cronológica dos mesmos.

Com relação ao equilíbrio, observou-se que 63,3\% dos escolares apresentaram a capacidade de equilibrar-se parcialmente desenvolvida, como mostra a figura acima, contradizendo os estudos de Rocha, Zagato Neto (2012), no qual afirmam que ro alunos avaliados na faixa etária de 6 anos, não apresentaram nível de desenvolvimento adequado para o elemento motor aqui discutido.

Silveira et al. (2005), relatam que muitos pais não permitem que a criança tenha de certa forma sua "liberdade", não permitem que as mesmas possam explorar os espaços, pular, correr, subir escadas, consequentemente, dificultam o 
aprimoramento de certas habilidades motoras imprescindíveis ao desenvolvimento humano, dentre delas o equilíbrio.

Os autores supracitados afirmam que após a aplicação dos testes motores em crianças na faixa etária de 2 a 6 anos, o esquema corporal foi a habilidade que obteve o menor desempenho, em torno de $51,1 \%$, contrapondo o presente estudo, no qual observou desempenho satisfatório quanto ao esquema corporal.

Conforme Mastroianni et al. (2004), o principal meio de comunicação e expressão da criança é o seu próprio corpo, diante disso defende-se que a mesma vivencie as experiências acumuladas através dos seus movimentos, todavia, quanto mais estimulada for à criança com atividades que envolvam o corpo, maior será a facilidade em comunicar-se com outras pessoas e com o meio.

Analisando a organização espacial, cerca de $96,6 \%$ dos escolares apresentaram este elemento motor adequado conforme a idade cronológica dos mesmos, contrariando o estudo de Rocha, Zagato Neto (20I2), no qual avaliaram io alunos com idade de 6 anos e constataram baixo nível de desempenho quanto a organização espacial avaliada. .

Le Boulch (2008), sugere que o indivíduo construa seu conhecimento a partir da sua interação com o meio físico e social. Existem nos espaços diferentes ações que o constituem como tal. Assim, um dos maiores desafios da psicomotricidade escolar é fazer com que o sujeito tenha condições de reconhecer, interferir e agir sobre estes espaços e dentro deles. Dessa forma, a primeira forma de desenvolver nas crianças as noções espaciais na idade pré- escolar é fazer com que ela explore o espaço físico da escola.

Almeida (2010), relata que para se conseguir o desenvolvimento das noções espaciais, devem ser desenvolvidas não somente atividades no papel ou em quadra, faz-se necessário considerar e admitir que é, no espaço social, o desenvolvimento mais produtivo e duradouro na idade infantil. A falta de um bom domínio espacial leva a criança a ter problemas de localização na escola, na cidade onde vive ou em um passeio qualquer, além de comprometer uma simples localização nos desenhos, nos mapas e, podendo, às vezes, até trocar letras de lado (letras espelhadas) porque não relaciona o traço à direção dele.

Convém destacar, ainda, conforme Silva e Beltrame (20II), apud Castaño (2002), que a linguagem se relaciona com o conhecimento do espaço, uma vez que as estruturas gramaticais, tais como as preposições "antes" e "depois", necessitam de uma compreensão da organização do espaço. Sendo assim, distúrbios nesta área motora podem, consequentemente, causar prejuízos na aprendizagem escolar.

Medina; Rosa; Marques (2006), realizaram um estudo sobre o desenvolvimento da organização temporal em crianças com dificuldades de 
aprendizagem, seja na escrita ou na leitura, nisso, avaliaram crianças na faixa etária de 8 e 9 anos e perceberam que a organização temporal da amostra obteve um médio desempenho, em torno de $32,4 \%$, considerado inferior à idade equivalente, opondo-se ao presente estudo, o qual constatou, cerca de 60\% dos escolares foram parcialmente positivos apresentando este elemento com médio desempenho, ou seja, em ambos estudos, os resultados foram semelhantes, conforme apresentado na figura acima. No entanto, conforme Baltazar (200I), as crianças que apresentam dificuldades de aprendizagem em leitura e escrita, na sua maioria, possuem a mesma forma de relacionar-se com as outras áreas trabalhadas no contexto escolar.

Os problemas de aprendizagem, na maioria das crianças, não estão associados a algum tipo de deficiência mental, mas, a algum problema associado ao desenvolvimento motor da criança. Os autores acima relatam, ainda, que a avaliação das capacidades desenvolvidas é essencial para diagnosticar problemas motores e suas consequências, fornecendo dados que viabilizem sugestões de intervenções que favoreçam o desenvolvimento global da criança em todos os seus aspectos (MEDINA: ROSA; MARQUES, 2006).

Destaca-se, ainda, que as dificuldades ou problemas de aprendizagem se originam de desordens provenientes de fatores facilmente removíveis, não necessariamente de causas orgânicas (GOMES; PAVÃO, 200I). Assim sendo, os problemas de aprendizagem verificados na maioria das crianças no estudo dos autores supracitados, não estão necessariamente ligados a algum tipo de deficiência mental. De acordo com Moreira, Fonseca e Diniz (200o), as crianças com dificuldades de aprendizagem evidenciam um conjunto de atributos, de características e comportamento que as diferenciam das crianças que aprendem com mais facilidade, condição essa que deve levá-la a um encaminhamento alternativo no ensino regular.

Rosa Neto (2002) salienta que a atividade motora é fundamental para o desenvolvimento global da criança, logo é através da exploração motriz que a criança desenvolve a consciência de si mesma e do mundo exterior. Dessa forma, a aquisição das habilidades motoras está vinculada integralmente ao desenvolvimento da percepção de corpo, espaço e tempo. Essas habilidades constituem componentes de domínio básico tanto para a aprendizagem motora quanto para as atividades de formação escolar.

Segundo Almeida (2007), a criança tem a capacidade de desenvolver fantasias, as quais auxiliam na estimulação do cognitivo, existindo uma profunda relação nos aspectos físico-motor, fatores biológicos e ambientais durante toda a infância, por ser uma habilidade importante para uma adaptação favorável da criança, pois lhe permite não só movimentar-se e reconhecer-se no espaç,o, mas também desencadear e dar seqü ê ncia aos seus gestos, por isso a importância em proporcionar experiências com o corpo e com a capacidade de descobrir sons e reproduzi-los. No estudo do autor supracitado, os alunos apresentam média de $77,8 \%$ no elemento organização temporal, nesse 
sentido, as crianças apresentaram desempenho satisfatório em relação ao tempo.

Crippa et al. (2003) abordaram em seus estudos o desenvolvimento da organização espacial, temporal e esquema corporal de crianças de 4 a 5 anos, encontrando normalidade no desenvolver espacial e temporal, no entanto observou-se atraso no desenvolvimento do esquema corporal, podendo este fato ser causado pelo uso excessivo dos recursos tecnológicos.

Segundo os autores acima, o déficit apresentado pode ser devido ao excessivo tempo gasto com jogos televisivos ou até mesmo à restrição de atividades como de respiração, simetria corporal, equilíbrio postural e outras. Embora estas crianças estejam em fase de desenvolvimento das capacidades perceptivas, temporais e de esquema corporal, o amplo desenvolvimento do conceito corporal é ponto crucial para o processo de melhoria gradual, pressupondo a base para o estabelecimento e aplicação no processo de aprendizagem das linguagens de leitura e escrita.

Assim, acredita-se serem necessárias atividades que auxiliem de forma completa no desenvolvimento da organização temporal das crianças, associadas a tarefas que viabilizem também o desenvolvimento do seu esquema corporal e organização espacial, tendo vista a grande participação destas áreas na realização das tarefas escolares, sobretudo a leitura e escrita (MEDINA; ROSA; MARQUES, 2006).

No que diz respeito à lateralidade, 70\% dos escolares do estudo apresentaram o elemento motor com desempenho compatível a idade real dos avaliados, assim observado na figura I. No entanto, Negrine (2009), indaga que a maioria das crianças apresenta lateralidade indefinida antes dos 6 anos de idade, por isso, este público acaba por não conseguir realizar certos movimentos como lançar uma bola. Nesse sentido, é necessário estimular o desenvolvendo de ambos os lados do corpo da criança, afim de que a mesma tenha pleno domínio na execução dos movimentos, seja utilizando sua lateralidade direita ou esquerda.

Amaro et al. (2010), analisaram o desenvolvimento motor em escolares com dificuldades na aprendizagem, como problemas de atenção, leitura, escrita, cálculo e socialização, os quais apresentaram escores inferiores em relação aos índices de desenvolvimento motor apresentados pelos escolares, percentualmente pôde-se constatar atribuição inferior e muito inferior em: $84,2 \%(n=32)$ na organização espacial, $8 \mathrm{I}, 6 \%(\mathrm{n}=3 \mathrm{I})$ na organização temporal, $79 \%(\mathrm{n}=30)$ no esquema corporal, $64,2 \%(\mathrm{n}=$ 24) no equilíbrio e $60,5 \%(n=23)$ na motricidade fina. A Motricidade Global apresentou índices de desenvolvimento insatisfatórios em 36,9\% ( $n=14)$ dos escolares.

Portanto, comparando com os resultados acima, a presente pesquisa, relata um desenvolvimento satisfatório em relação aos elementos motricidade fina $(93,4 \%)$ e organização espacial $(96,6 \%)$, assim representado na figura I, apresentando, desta forma, maiores percentuais de desempenho. No entanto, em relação aos elementos motricidade global (40\%), equilíbrio (23,3\%) e organização temporal (33,6\%), o 
desenvolvimento foi considerado abaixo da média, porém no estudo de Amaro et al. (2010), tais elementos tiveram melhor desempenho positivo. Ressalta-se, ainda, que dentre todos os elementos motores caracterizados no estudo, o equilíbrio (23,3\%), foi o elemento que obteve menor desempenho positivo.

\section{Considerações finais}

Diante do exposto, pode-se constatar no presente estudo que na caracterização do desempenho motor, a maioria dos escolares encontra-se dentro da normalidade, tendo o elemento psicomotor da organização espacial com avaliação positiva entre os avaliados, enquanto a motricidade fina apresentou-se como o elemento psicomotor de desempenho negativo.

A partir da aplicação dos testes psicomotores, pode-se inferir que o brincar está escasso na vida das crianças, pois pode-se conferi que a escola não proporciona um ambiente agradável com brinquedos, jogos e brincadeiras. Tal fato foi perceptível pelo momento prazeroso proporcionado às crianças por meio da aplicação dos testes psicomotores do referido estudo, logo, as mesmas mostraram-se satisfeitas ao realizarem as atividades propostas.

No entanto, os dados da pesquisa ainda se mostram insatisfatórios para concluir a caracterização do desempenho motor dos escolares, afinal, foi realizado apenas um teste motor de cada elemento, bem como a população amostral não englobou todo o público pertinente e, por esta razão, sugere-se o aumento de estudos de cunho científico relacionados ao assunto em questão.

Dessa forma, não se chegou ao fim dessa discussão, pois considera-se a pesquisa como algo inacabado e que sempre se faz necessária. Muitos outros diálogos acerca do desenvolvimento da criança e do brincar se fazem precisos, todavia, acredita-se que esse estudo possa contribuir com futuras pesquisas sobre o tema.

Diante das evidências, convém afirmar que somente as aulas de Educação Física, por mais estimulantes que possam ser, não garantem a total eficácia do desenvolvimento motor, portanto, é fundamental estimular os elementos motores supracitados no estudo ainda nos primeiros anos da infância a fim de que possam contribuir no desenvolvimento global da criança.

\section{Referências Bibliográficas}

AlMEIDA, G.M.F.D. Deficiência Mental: Avaliação e classificação do desenvolvimento motor. 2007,I44 f. Trabalho de Conclusão de Curso (Mestrado) Universidade do Estado de Santa Catarina, Florianópolis, 2007.

ALMEIDA, G.P. de. Teoria e prática em Psicomotricidade: jogos, atividades lúdicas, expressão corporal e brincadeiras infantis. Rio de Janeiro, RJ: Wak, 6. ed. 2010. 
AMARO, K.N.; JATOBÁ, L.; SANTOS, A.P.M. dos; ROSA NETO, F. Desenvolvimento motor em escolares com dificuldade de aprendizagem. Movimento \& Percepção, v. II, n. I6, p. 39-47, 2010.

BALTAZAR, M. O tratamento das dificuldades de aprendizagem de leitura e escrita à luz da psicopedagogia construtivista. Revista Reflexão e Ação, Santa Cruz do Sul, v. 9, n. I, p. 37- 46, 2001.

BESSA, L.A.S.; MACIEL, R. M. A Importância da Psicomotricidade no Desenvolvimento das Crianças nos Anos Iniciais. Revista Científica Multidisciplinar Núcleo do Conhecimento. ano oI, ed. oI, v. I2, p. 59-78, 2016.

CAETANO, M. J. D; SIlveirA, C. R. A; GOBBI, L. T. B. Desenvolvimento motor de pré- escolares no intervalo de 13 meses. Revista Brasileira de Cineantropometria e Desempenho Humano, v. 7, n. 2, p. 05-13, 2005.

COSTA JR, D. Psicomotricidade e Desenvolvimento Motor. Valinhos: 2017.

COSTA, R. M.; SILVA, E. A. A. Escala de desenvolvimento motor de rosa neto: estudo longitudinal em uma escola da rede particular de ensino de CuiabáMT. Eletrônica do Univag, Cuiabá, n. 4, p. 51-64, jan. Disponível em:

〈http://www.periodicos.univag.com.br/index.php/CONNECTIONLINE/article/vie $\mathrm{w} / \mathrm{r} 33$

>. Acesso em: 20 de out. de 2019.

CRIPPA, L. R.; SOUZA, J. M.; SIMONI, S.; ROCCA, R. D. Avaliação motora de préescolares que praticam atividades recreativas. Revista de Educação Física/UEM, Maringá, v. I4, n. 2, p. 13-20, 2003.

GALlAHUE, D. L.; OZMUN, J. C.; GOODWAY, J. D. Compreendendo o desenvolvimento motor: bebês, crianças, adolescentes e adultos. 7. ed. Porto Alegre: AMGH, 2013.

GAllahUE, D. L; OZMUN, J. C. Compreendendo o desenvolvimento motor: bebês, crianças, adolescentes e adultos. São Paulo: Phorte, 20or.

GOMES, C. C. P.; PAVÃO, S. M. O. Dificuldades de aprendizagem. Revista Educação, Santa Cruz, v. 5, n. 2, p. 25-31, 2001.

LE BOUCH, J. O corpo na escola no século XXI: práticas corporais. Phorte, 2008. LEVITT, S. O tratamento da paralisia cerebral e do retardo motor. São Paulo: 
Manole. 200I.

LUSSAC, R.M.P. Psicomotricidade: história, desenvolvimento, conceitos, definições e intervenção profissional. Revista Digital - Buenos Aires, ano 13, n. I6, nov. 2008.

MASTROIANNI, E. de C.Q. et al. Abcd no Lar - Aprender, Brincar, Crescer e Desenvolver no Laboratório de Atividades Lúdico - Recreativas. Ed. Unesp. p.557-67. São Paulo, 2004.

MEDINA, J.; ROSA, G. K. B.; MARQUES, I. Desenvolvimento da organização temporal de crianças com dificuldades de aprendizagem. Revista da Educação Física/ UEM, v.17, n.I, p. 107-116, 2006.

MOREIRA, N. R.; FONSECA, V.; DINIZ, A. Proficiência motora em crianças normais e com dificuldades de aprendizagem: estudo comparativo e correlacional com base no teste de proficiência motora de BruininksOseretsky. Revista de Educação Física/UEM, Maringá, v. II, n. I, p. II-26, 2000.

NEGRINE, A. Educação Psicomotora: a lateralidade e a orientação espacial. Porto Alegre: Pallott, 2009.

NEVES, J. L. Pesquisas Qualitativas - Característica, Usos e Possibilidades. Cadernos de Pesquisas em Administração. São Paulo, v. I, no 3, 2o SEM./1996.

OlIVEIRA， C.C.de O.; CAVALCANTE NETO, J.L.; PALHARES, M.S.; Caracterização

Motora de Escolares com Transtorno de Déficit de Atenção e Hiperatividade. Caderno Brasileiro de Terapia Ocupacional, v. 26, n.3, p. 590-60o, 2018.

OLIVEIRA, D. da S.; OLIVEIRA, I.S de; CATTUZZO, M.T. A influência do gênero e idade no desempenho das habilidades locomotoras de crianças da primeira infância. Revista Brasileira de Educação Física e Esporte, v. 27, n. 4, p. 647-655, 2013.

ROSA NETO, F. Manual de avaliação motora para terceira idade. Porto Alegre: Artmed Editora, 2002.

ROSA NETO, Francisco. (2002) Manual da Avaliação Motora. Porto Alegre: Artemed. 3. ed. rev. e aum (2015).

ROSA NETO, F., et al. Desenvolvimento motor de crianças com indicadores de dificuldades na aprendizagem escolar. Revista Brasileira de Ciência e Movimento, v. I5, n. I, p. 45-52, 2008. 
ROSA, G.K.B.; MARQUES, I.; MEDINA-PAPST, J.; GOBBI, L.T.B. Desenvolvimento motor de criança com paralisia cerebral: disponível para intervir. Revista Brasileira de Educação Especial , v. I4, n. 2, p. 163-176, 2008.

ROCHA, J.C; NETO, N.Z. Psicomotricidade: Estimulação das Habilidades Motoras, Cognitivas e Sócio Afetivas- Centro Universitário Católico Salesiano Auxilium 2012.

SILVA, J; BELTRAME, T. S. Desempenho Motor de aprendizagem em escolares com idade entre 7 e Io anos. Motricidade, Florianópolis, v. 7, n. 2, p. 57-68, 201 I.

SILVEIRA, C.R.A; GOBBI, L.T.B; CAETANO, M.J.D; ROSSI, A.C.S; CANDIDO, R.P. Avaliação Motora De Pré-Escolares: Relações Entre Idade Motora E Idade Cronológica. Revista Digital. Buenos Aires EFDeportes, ano ıо, n. 83, 2005. Disponível em:〈http://www.efdeportes.com/efd83/avalia.htm〉. Acesso em: 20 out. 2019.

SOCCOL, C.P. Escala de Desenvolvimento Motor em crianças de uma Creche Municipal de Cuiabá-Mt. In: Seminário nacional corpo e cultura: políticas e cotidianos da formação em educação física, 2., 2009, Cuiabá. GTT ATIVIDADE FÍSICA E SAÚDE E TREINAMENTO ESPORTIVO. Cuiabá: Seminário Do Cbce, 2009. p. 5 II.

SOUZA, M. S. D.; ZANELLA, L. W.; BANDEIRA, R. P. F.; SILVA, A. C. R.; VALENTINI, N. C. Meninos e meninas apresentam desempenho semelhante em habilidades motoras fundamentais de locomoção e controle de objeto. Cinergis, v. I5. n. 4, p. 186-190, 2014.

SOUZA, E. O. A importância das brincadeiras e dos jogos com ludicidade nas aulas de educação física. AVM - Faculdade Integrada, Rio de Janeiro, Jul, 2007. Disponível em:

http://www.avm.edu.br/monopdf/7/ELAINE\%20OLIVEIRA\%2oDE\%2oSOUSA.p df, acesso em 20 de out. de 2019.

XISTO, P. B.; BENETTI, L. B. A Psicomotricidade: Uma ferramenta de ajuda aos professores na aprendizagem escolar. Monografias Ambientais REMOA/UFSM, v.8, p. 18424-1836, 2012. Disponível em: 〈https://periodicos.ufsm.br/remoa/article/view/6190/3690〉. Acesso em: 20 out. 2019. 